\title{
ESTUDOS
}

\section{A institucionalização da Escola Normal no Brasil $(1870-1910)^{\star}$}

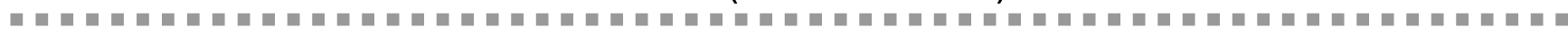

Wojciech Andrzej Kulesza

Palavras-Chave: magistério primário; instituições escolares; história da educação.
A criação de Escolas Normais públicas nas províncias teve de se acomodar ao ensino secundário ministrado nos Liceus, essencialmente masculinos e dedicados à preparação para o ingresso no ensino superior, e que tiveram sempre como modelo o Colégio Pedro II no Rio de Janeiro. Os diversos Liceus provinciais constituíram referência fundamental para o desenvolvimento do ensino normal, emprestando seus professores, suas instalações e seus regulamentos para as novas escolas. Nesse confronto entre as normas emanadas do poder central e os ditames locais, foram tentadas diversas formas de institucionalização nas quais os dois educandários acabaram influenciando-se mutuamente, ao mesmo tempo que foram se configurando como escolas distintas. Como resultado desse processo, sem solução de continuidade na transição do Império para a República, emerge durante a primeira década de nosso século, em todo o território nacional, uma Escola Normal essencialmente feminina, dotada de escolas-modelo anexas destinadas à prática pedagógica, e que desencadearam o processo de profissionalização do nosso magistério primário.

\section{Introdução}

A Reforma Leôncio de Carvalho de 1879 exprime institucionalmente os anseios de renovação educacional concomitantes aos movimentos políticos e econômicos em busca de uma nova ordem social para a nação brasileira, que se intensificaram no início daquela década e que desembocaram na abolição da escravatura e na constituição de um governo republicano no final da década seguinte. No campo da educação popular, tradicionalmente deixada a cargo das províncias desde o Ato Adicional de 1834, embora a reforma tivesse valor legal apenas no município da Corte, estimulavase a criação de Escolas Normais em todas as províncias, acenando-se inclusive com auxílio econômico do governo central. A partir daí, as múltiplas experiências de estabelecimento de Escolas Normais nas províncias, iniciadas já em 1835 com a fundação de uma Escola em Niterói, passam a tomar por referência as diretrizes emanadas do Rio de Janeiro, especialmente depois da criação de uma Escola Normal nessa cidade, em 1880, como resultado também daquela reforma.

A entrega da direção dessa Escola ao professor positivista da Escola Politécni$\mathrm{ca}$, Benjamin Constant, colocou o movimento em favor da formação de professores primários na vanguarda das transformações sociais em curso. As tentativas de centralização do Ensino Normal, preconizadas por Leôncio de Carvalho, tiveram um forte impulso graças à Carta-Circular do ministro do Império, de 26 de novembro de 1881. Nessa carta, transcrita na sua essência em Brzezinski (1987, p. 39), o ministro vinculava a criação de escolas normais ao estabelecimento de mesas 
gerais de preparatórios nas províncias para o ensino secundário. Reivindicação permanente, a equiparação dos exames de preparatórios realizados nos Liceus provinciais com aqueles feitos pelo Colégio Pedro II, cuja aprovação garantia aos alunos o acesso direto aos cursos superiores no Império, era vista como única solução para impedir o esvaziamento daquelas escolas secundárias. Embora estivessem a cargo das províncias, os Liceus, dado seu caráter propedêutico ao ensino superior, constitucionalmente regulado com exclusividade pelo poder central, estavam na dependência direta das normas legais emanadas na Corte. Como demonstrou Maria de Lourdes Mariotto Haidar em seu clássico trabalho sobre o ensino secundário no Império (1972), essa foi a razão básica, associada à freqüência livre $\mathrm{e}$ aos exames parcelados, de não se ter constituído uma verdadeira escola secundária naquele período histórico. Lugar de "aulas avulsas" oferecidas pelas diversas "cadeiras", as escolas secundárias jamais deram organicidade ao título de bacharel em Ciências e Letras, conferido, aliás, a pouquíssimos egressos dessas escolas. $O$ fato é que o aceno explícito do governo central, constante da carta do ministro acima referida e que já havia sido provisoria- mente implantado na década anterior, de estabelecer "mesas de exames gerais de preparatórios" em função da existência de escolas normais nas províncias, de certa forma, equiparou oficialmente essas duas escolas secundárias. Segundo Tanuri (1979, p. 23), o número de Escolas Normais em funcionamento no Brasil passou de quatro em 1867, para 22 em 1883, comprovando a eficácia das iniciativas do poder central, espicaçado pela sociedade civil da Corte, em sensibilizar os representantes provinciais no parlamento para essa questão.

Assim, a formação de professores para as escolas primárias no Brasil, exigidas pela nova ordem social, nasce umbilicalmente vinculada aos tradicionais Liceus. Tradicionalmente destinados à formação das elites masculinas, essas escolas, como iremos ver, influenciarão fortemente as iniciativas de criação de Escolas Normais, especialmente nos momentos iniciais. Estas, por sua vez, dado seu duplo caráter de escolas secundárias e profissionais, preponderantemente femininas, virão a influenciar também suas congêneres masculinas, mas, principalmente, nortearão o desenvolvimento da instrução primária, tanto pública como privada, nos estados, durante a Primeira República.

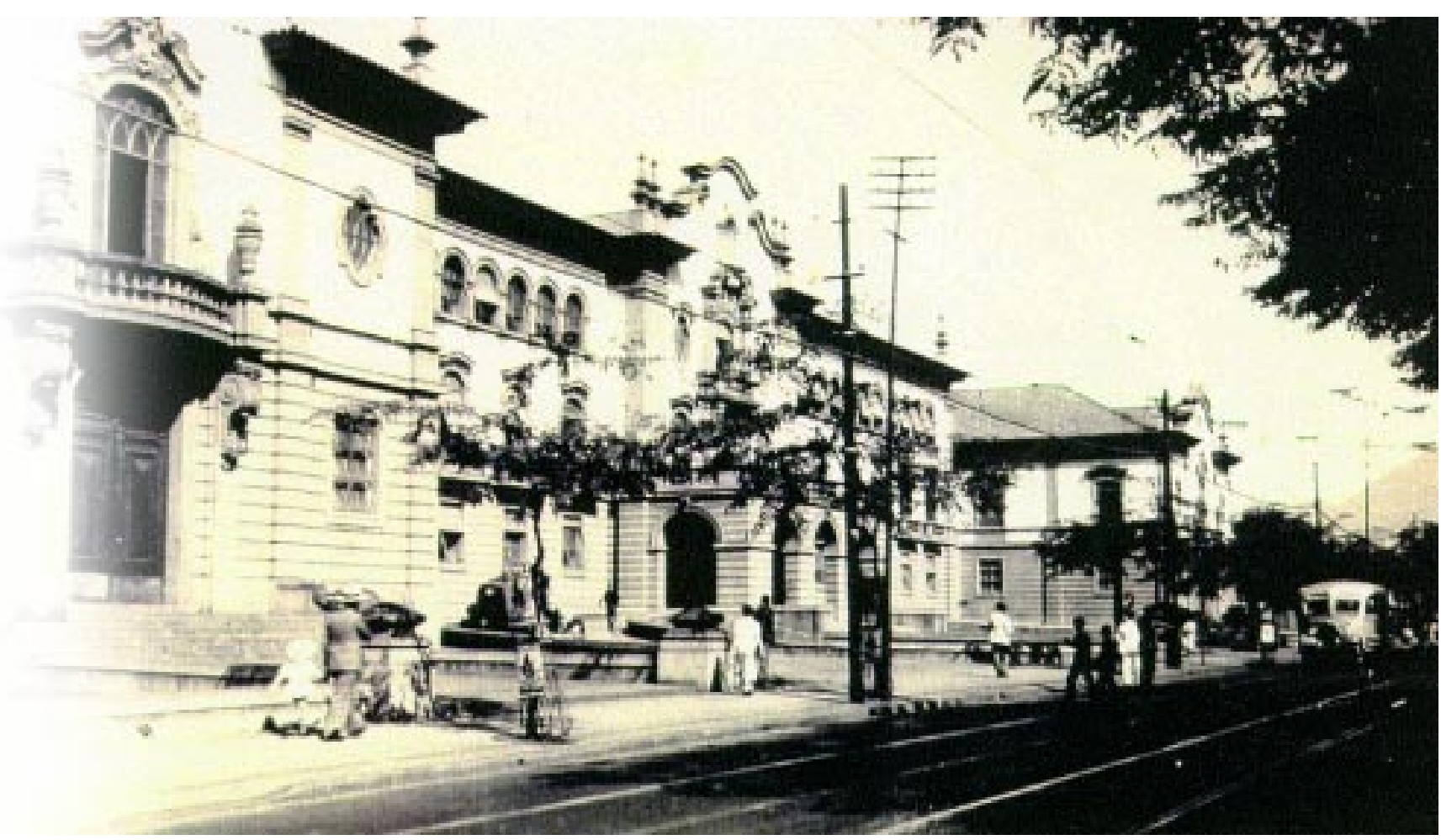

Figura 1 - Instituto de Educação do Rio de Janeiro [1930?]. 


\section{Formas de institucionalização}

Antes de fundarem propriamente uma Escola Normal, muitas províncias criaram um Curso Normal anexo ao Liceu simplesmente pela adição de uma cadeira de $\mathrm{Pe}$ dagogia ao currículo, aligeirando-se a parte de formação geral e reservando-se a prática profissional para ser exercida junto a alguma escola primária pública. Esse foi o caso típico do Piauí. Nessa província, um Curso Normal foi criado em 1864, posto a funcionar em 1866 e suprimido em 1867. Criado novamente junto ao Liceu em 1871 , foi extinto em 1874. Em resposta ao apelo da carta ministerial supracitada, foi criada uma Escola Normal em 1882 para funcionar junto ao Liceu e que foi fechada em 1888 (Olympio, 1922, p. 55-56). Justificando esta medida, o presidente Viveiros de Castro nos dá uma lúcida análise da situação:

Entre nós, porém, anexa-se a Escola Normal ao Liceu, dá-se aos lentes deste uma pequena gratificação para regerem as cadeiras daquela e acredita-se, pelo que se deduz dessa balbúrdia, e do programa das disciplinas, que onde houver uma cadeira de Pedagogia e Metodologia, aí se terá uma Escola Normal... Nada mais irrisório... (Moacyr, 1939, p. 306).
Já em 1872, o presidente da província do Amazonas, ao determinar que a aula de Pedagogia do Liceu funcionasse à tarde em um dos edifícios de uma escola primária, sentenciava: "deste modo a aula de Pedagogia reunirá o ensino teórico ao prático. E esta a única diferença entre uma Escola Normal e um Liceu" (Moacyr, 1939, p. 51).

Essa solução era extremamente atraente do ponto de vista econômico, dada a constante falta de recursos para a instrução pública nos cofres provinciais. Utilizando as mesmas instalações físicas, os mesmos professores (exceto o professor de Pedagogia que, muitas vezes, era um professor do Liceu que acumulava duas cadeiras), este modelo foi tentado, com modificações, na grande maioria das províncias agrupandose, significativamente, em algumas delas as aulas de Pedagogia na "cadeira de ensino normal", como ocorreu na Paraíba (Mello, 1996, p. 56). Em São Paulo, onde o estabelecimento de uma escola secundária pública semelhante aos Liceus só se deu na capital após a Proclamação da República, foi criada uma Escola Normal masculina em 1875 para funcionar numa das salas do curso de preparatórios anexa à Faculdade de Direito, demonstrando, assim, que a mesma solução era utilizada em condições diferentes, mas sempre atrelada ao ensino secundário já existente (Tanuri, 1979, p. 29).

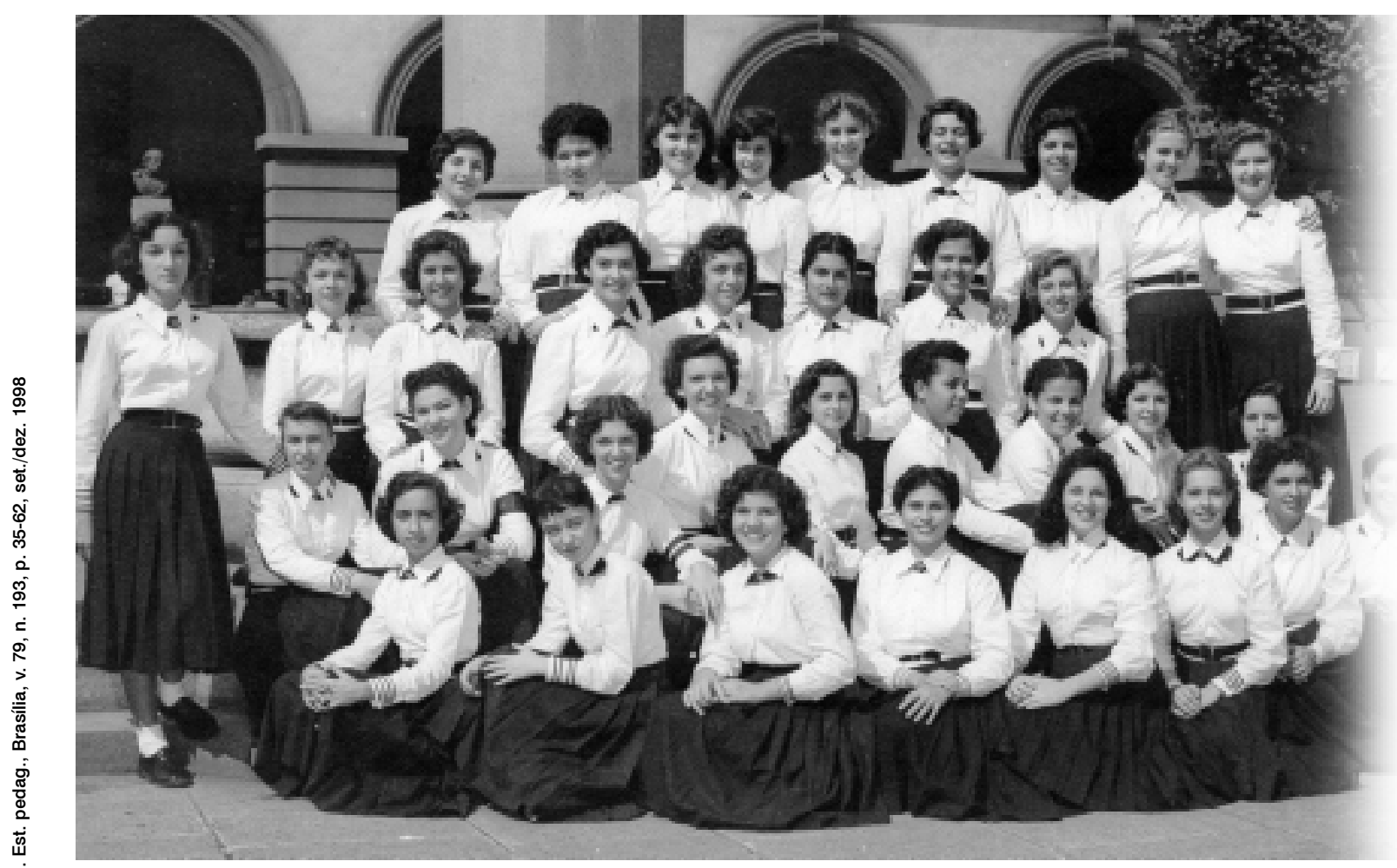

Figura 2 - Grupo de alunas do Instituto de Educação do Rio de Janeiro (turma de 1954).

Fonte: Arquivo particular de Rita M. Neves Braz 
Muito embora se pensasse num curso para ambos os sexos, é claro que essas condições acabaram restringindo o acesso das mulheres e, na prática, essa opção era reservada essencialmente aos homens. Como afirmou o presidente da província do Paraná em 1888 sobre a Escola Normal: "Funcionando como está juntamente com o Instituto Paranaense [Liceu local], não há como esperar-se que ela seja freqüentada por alunas" (Moacyr, 1939, p. 344). Uma ilustração dramática das dificuldades de se concretizar a co-educação dos sexos, estabelecida pioneiramente no ensino secundário em Pernambuco pela reforma de 1875 de sua Escola Normal, é-nos dada pelo relatório do inspetor de ensino daquele ano, João Barbalho:

A freqüência é comum e simultânea aos alunos mestres quer de um quer de outro sexo, sendo os assentos dispostos nas aulas em duas seções, uma ao lado da outra, para cada sexo, ficando em frente a do professor. Os pais das alunas ou pessoas que as conduzem podem assistir as aulas, independente de licença e com estes quaisquer pessoas morigeradas e decentemente vestidas (Bello, 1978, p. 123).

Essa experiência pioneira de Pernambuco seria interpretada de forma exagerada na época, dando origem assim na historiografia a uma falácia pitoresca. Assim, por exemplo, em 1880, o diretor da Escola Normal de Niterói, defendendo seu sistema de vigilância montado para controlar a coeducação então implantada em sua escola, dizia que o mesmo era muito superior ao de Pernambuco, "que mandara levantar uma parede pelo centro da sala em frente à cadeira do professor, para que homens e mulheres não se comunicassem" (Villela, 1992, p. 33). No Brasil, legalmente, a coeducação seria instituída pela reforma Leôncio de Carvalho, mas apenas para meninos e meninas de até 10 anos em classes regidas necessariamente por professoras. Saffioti (1976, p. 202), no seu clássico trabalho sobre a mulher no Brasil, já havia salien-tado o papel inovador da Escola Normal do ângulo da co-educação "porquanto, o princípio da segregação sexual continuaria em vigor ainda por muito tempo nas escolas secundárias".

Analisando o conteúdo da cadeira de Pedagogia assim criada e a pouca ênfase dada à prática pedagógica, pode-se con- cluir que esse curso tinha por objetivo a formação de dirigentes para o ensino público. A restrita existência de vagas para essas funções, aliada à baixa remuneração e ao seu reduzido prestígio social, fizeram com que poucos elementos da clientela dos Liceus, essencialmente pertencente à elite local, seguissem por esse caminho. Outro fator que contribuiu para o fracasso desse modelo foi a permanência da possibilidade de se ingressar no magistério sem a necessidade do diploma de normalista. Mesmo que fosse garantido o ingresso imediato na carreira, sem a necessidade de exames, a facilidade destes andava pari passu com o desprestígio da profissão. Em Sergipe, o diretor de instrução pública, tentando aliciar alunos para a recém-criada Escola Normal em 1871, teria ouvido deles que "quando quisessem ser professores públicos se preparariam em 15 dias a um mês" (Mendonça, 1958, p. 169). Com o esvaziamento desses tipos de curso devido ao processo de feminização do magistério, essa fórmula de preparação de professores foi rapidamente abandonada.

Um outro modelo, adotado nas províncias em função dos estímulos do governo central a partir da reforma de 1879 , foi transformar o Liceu em Escola Normal, estabelecendo-se gradações em seu interior, ficando o grau mais baixo de formação destinado aos futuros professores. Se o governo central, mediante a prerrogativa constitucional que the assegurava o controle do ensino superior, possuía mecanismos legais para garantir uma certa uniformidade no ensino ministrado nos Liceus provinciais, isso não acontecia no ensino primário e, em decorrência, nas Escolas Normais. Esta questão assume importância decisiva num quadro político em que o federalismo constituía importante bandeira dos republicanos. Daí as freqüentes tentativas de centralização do ensino normal, esboçadas já em 1874 pelo ministro João Alfredo Correia de Oliveira (Almeida, 1989, p. 144) e sistematizadas por Leôncio de Carvalho, embora circunscritas legalmente apenas ao município da Corte.

Incapacitado de impor sua proposta legalmente, a partir de então o governo utiliza uma arma sensível para as elites: a permissão da instalação de "mesas gerais de exames de preparatórios" nas províncias. Reivindicação permanente, a equiparação dos exames de preparatórios realizados nos Liceus pro- 
vinciais com aqueles feitos no Colégio Pedro II, cuja aprovação garantia aos alunos o acesso direto aos cursos superiores no Império, havia sido obtida em 1873, por obra do ministro João Alfredo. Com a reforma Leôncio de Carvalho, essa permissão só seria concedida àquelas províncias que mantivessem um Liceu com um programa de estudos equiparado ao do Colégio Pedro II.

Valendo-se de uma abertura sabiamente colocada por Leôncio de Carvalho na legislação, que facultava às províncias, enquanto não houvesse um Liceu equiparado, a criação de Escolas Normais estruturadas à semelhança da Escola Normal do Rio de Janeiro como condição para a instalação das mesas de exames, o governo exorta em 1881, por meio de CartaCircular, para que os presidentes das províncias se empenhassem na instalação dessas escolas.

Na Paraíba, por exemplo, a criação da Escola Normal em 1884 foi feita transformando-se o Liceu em Escola Normal de dois graus, cabendo ao primeiro grau, segundo o presidente da província, a função de

preencher o elevado desígnio, o que naturalmente mais influiu no espírito da reforma, de preparar professores mais capazes para o exercício do magistério, eliminando os moldes já gastos, condenados por uma longa experiência (Mello, 1996, p. 63).

Com a duração de dois anos e destinada a ambos os sexos, essa Escola foi logo transformada em Externato Normal apenas para mulheres, funcionando em prédio próprio separado do Liceu, que já no ano seguinte seria restabelecido. Só em 1905 funcionaria efetivamente uma seção masculina da Escola Normal, valendo-se ainda das instalações do Liceu.

Em Goiás, a reforma de 1884 anexava as aulas de instrução secundária à Escola Normal, momentaneamente elevada à condição de instituição escolar principal (Canezin, Loureiro, 1994, p. 30). A crescente demanda da ocupação de professor pelas mulheres contribuiu para a concepção desse modelo, uma vez que a deficiente oferta de instrução primária de qualidade para as mulheres dificultava seu aproveitamento nas cadeiras do Liceu, cujo nível de exigência era deter- minado diretamente pelos exames preparatórios para o ingresso nos cursos superiores. A reforma da instrução pública de 1881 realizada em Sergipe, que iria prevalecer por cerca de dez anos, transformou o Ateneu numa Escola Normal de dois graus, sendo o primeiro claramente concebido para a formação de professores e o segundo como preparatório para os cursos superiores (Nunes, 1984).

Na província de Santa Catarina, em 1883, o Ateneu local foi transformado em Instituto Literário e Normal, onde funcionava um curso de dois anos para a preparação de professores (Fiori, 1991, p. 63). Também no Paraná o Liceu local (Instituto) foi extinto em 1883, restando somente uma Escola Normal (Moacyr, 1939 , p. 310). Essa solução continuaria a ser adotada após a proclamação da República, numa demonstração inequívoca da permanência da velha estrutura social na área educacional. Dessa forma, em 1890, na província do Amazonas, o Liceu foi extinto para a criação de um Instituto Normal Superior, para três anos depois ser anexado ao Ginásio Amazonense, este sim equiparado ao então Ginásio Nacional (Bittencourt, 1981 , p. 29) e, em 1893, reúnem-se em Pernambuco a Escola Normal e o Liceu Provincial num mesmo Instituto, denominado Benjamin Constant. Embora possamos relacionar essas medidas com a decadência do ensino secundário dos Liceus e o incentivo do poder central naquela época para a criação de Escolas Normais, essa fórmula já havia sido adotada no Espírito Santo em 1869 (Coutinho, 1993, p. 77) e seria adotada também em outras ocasiões até a completa autonomização da Escola Normal dos Liceus, concluída, ao menos em termos físicos, por volta de 1910 em todo - País. A breve carreira desse tipo de solução deveu-se muito mais ao prestígio dos tradicionais Liceus no âmbito das províncias (depois Estados) e à permanência de seu caráter propedêutico ao ensino superior para a elite masculina. No seu afã de enaltecer a importância social da Escola Normal, uma autora chegou a afirmar que "a verdadeira causa" do fracasso desse modelo em Goiás estaria numa suposta "rivalidade" entre os dois cursos secundários, afirmação evidentemente equivocada (Brzezinski, 1987, p.107). 
Apesar de esse modelo ter também seus atrativos do ponto de vista financeiro, ele tinha dificuldades de implantação, exatamente porque a presença das mulheres obrigava a um desdobramento de professores e de espaço físico. Outra dificuldade foi a necessidade de criação de escolas anexas, também recomendada pela reforma de 1879 , nas imediações ou mesmo nas próprias dependências das Escolas Normais. Como essas turmas eram regidas preferencialmente por professoras em estreita interação com o lente de $\mathrm{Pe}$ dagogia, que as utilizava para ministrar suas aulas práticas, e devido ao fato de essas professoras, muitas vezes, acabarem assumindo disciplinas práticas do Curso Normal, a feminização da formação para o magistério inviabilizava seu funcionamento junto a uma instituição essencialmente masculina. $\mathrm{Na}$ Paraíba, o regulamento de 1892 dispunha no seu artigo 40 que "as cadeiras de desenho e música, trabalhos de agulha e prendas domésticas" seriam regidas pelas duas professoras da escola primária anexa (Paraíba, 1913, p. 15), e no Ceará, o regulamento de 1890 suprimia a escola primária anexa masculina, "mantendo-se, entretanto, a do sexo feminino, onde as normalistas faziam a prática pedagógica e recebiam, aos sábados, noções de prendas domésticas" (Souza, 1955, p. 112). Na prática, por causa da crescente regência das classes do ensino primário por mulheres, desvirtuou-se completamente a idéia, tal como está expressa no regulamento do Curso Normal de Santa Catarina de 1883, no qual era instituída uma escola primária anexa "para nela se habilitarem os normalistas, na prática das maneiras e método de ensino" (Fiori, 1991, p. 63). Aliás, esta é uma das raras ocasiões encontradas em que se usou a palavra normalista no gênero masculino no período estudado.

A necessidade de uma separação da Escola Normal do Liceu vai pouco a pouco se tornando senso comum pelas províncias, dada a demanda feminina crescente pelo magistério e a permanência de um sistema educacional que reservava o ensino superior para os homens. Em 1889, antes da República, Souza Bandeira, presidente do Mato Grosso, constatando que nenhuma aluna cursava a Escola Normal anexa ao Liceu, extingue-a, criando em prédio próprio um externato para o sexo feminino, justificando assim sua decisão:

Não é preciso dizer mais para patentear o defeito da extinta repartição. Ela che- gou ao extremo resultado de excluir do ensino normal quem melhor e mais vantajosamente pode desempenhar a árdua profissão de mestre, a mulher. A escola primária é uma continuação da família; bem como no lar doméstico, a mulher menos prendada afeiçoa o espírito e o coração de seus ternos filhos com aquele segredo que os pais mais ilustrados não praticam, nem compreendem, assim também na escola elementar, destinada a auxiliar e aperfeiçoar o trabalho da família, vem a ser uma inconseqüência abandonar ao homem aquela tarefa (Marcílio, 1963, p. 102).

$\mathrm{E}$, numa clarividente antecipação do futuro, acrescentou: "Prevejo que um dia essa disposição terá forçosamente que revestir caráter mais absoluto, no sentido de confiar-se exclusivamente ao sexo feminino, a regência de todas as escolas primárias" (Marcílio, 1963).

Uma ilustração conspícua dessa tendência irreversível de feminização do magistério nos é dada pelos acontecimentos no Rio Grande do Norte, onde a Escola Normal foi criada como um curso profissional anexo ao Liceu local (Ateneu), em 1896. Em 1898, estavam matriculados nos três anos do curso apenas seis alunos, sendo o curso extinto em 1901 para abrir-se novamente, "para ambos os sexos", em 1908 (Araújo, 1979, p. 161163). Em Alagoas, onde uma "cadeira de Escola Normal" fora criada em 1869 junto ao Liceu, institucionalizando-se assim uma Escola Normal masculina, já em 1875 cogitavase de ela ser freqüentada somente por muIheres e, a partir de 1887, "as moças tomaram conta do Curso Normal" (Vilela, 1982, p. 150). Sintomaticamente, quando em 1906 é inaugurada a primeira Escola Normal pública por João Pinheiro da Silva na moderna Belo Horizonte, ela se abre exclusivamente para a formação de professoras.

Uma terceira modalidade de constituição de Escolas Normais nas províncias, menos institucionalizadas, mas de raízes históricas mais antigas, baseou-se na extensão da escolarização de órfãos entregues a instituições dirigidas por ordens religiosas. Nesse caso, no período que estamos considerando, a clientela já era predominantemente feminina e o curso tinha um caráter eminentemente prático, com as alunas ajudando na educação das órfãs menores. No Rio Grande do Sul, só se conseguiu concretizar a lei sancionada em 1860 autorizando a criação de uma Escola Normal na província 
em 1869, graças ao concurso do Padre Cacique, nomeado seu primeiro diretor, que antes dirigia um colégio religioso destinado a abrigar meninas órfãs, as quais, levadas por ele, contribuíram em grande número para compor o alunado feminino da nova escola (Desaulniers, 1997, p. 106-109). No Pará, a Escola Normal instalada em 1871, funcionava no Liceu para os homens e no Colégio N. Sa. do Amparo para as mulheres. Esse colégio, pelo regulamento de 1869, tinha "por fim proteger as meninas órfãs pobres e desvalidas e as expostas, proporcionando-lhes a conveniente educação e ensino" (Moacyr, 1939, p. 112). O presidente de Sergipe criou em 1877 uma Escola Normal no Asilo de N. Sa da Pureza, à qual seriam admitidas, nos termos do regulamento, as asiladas e alunas externas (Moacyr, 1939, p. 63). Em São Paulo, há muito que se cogitava da criação de uma Escola Normal junto ao Seminário da Glória, destinado a órfãs, efetivando-se esta iniciativa em 1876. Mesmo que Escolas Normais não tenham sido neles formalmente instaladas, esses seminários serviram para prover de professoras o magistério primário.

Podemos também incluir nesse modelo as iniciativas de várias Sociedades de Instrução, geralmente dirigidas à formação de moças "desvalidas" e com o intuito claro de profissionalização das alunas. No Maranhão, a Sociedade Literária 11 de Agosto mantinha, em 1872, uma Escola Normal que funcionava das $6 \mathrm{~h} 30$ às $8 \mathrm{~h}$ e das $5 \mathrm{~h}$ às $9 \mathrm{~h}$, destinada, portanto, a trabalhadores (Saldanha, Melo, 1996, p. 23). Em 1908, em face da inexistência de escolas de formação de professores no Piauí, a Sociedade Auxiliadora de Instrução instala uma Escola Normal Livre, já agora destinada às "patrícias que ali procuravam educar o espírito" (Olympio, 1922 , p. 98). Essas iniciativas, que contavam com franco subsídio dos cofres públicos, foram preferencialmente adotadas nos Estados onde regiões distintas daquelas em torno da capital começaram a ter um maior desenvolvimento econômico, forçando o governo estadual a subsidiar a iniciativa privada naquelas áreas, geralmente com o suporte de ordens religiosas, como é ilustrado claramente pela atuação das irmãs dominicanas em Goiás (Canezin, Loureiro, 1994, p. 54-65). A formação de professoras em escolas confessionais sofrerá um forte impulso a partir de 1920, já num cenário de necessidade e reconhecimento do magistério feminino como profissão, fiscalizadas, mas também, subsidiadas pelos Estados.

\section{Conclusão}

Acompanhando as transformações sociais que ocorriam em todo o território brasileiro, as Escolas Normais, gradativamente, conformam-se aos projetos políticos das oligarquias locais, cada vez mais imbuídos da necessidade de uma educação primária para as classes populares. Apesar dos anseios de renovação estimulados pelo advento do regime republicano, que geraram um breve "entusiasmo pela educação" voltado para a alfabetização capaz de habilitar os eleitores ao direito de voto, percebe-se muito mais uma continuidade do que uma ruptura com as iniciativas tomadas no final do Império, no que tange ao desenvolvimento institucional do Ensino Normal. Se bem que, como diz Nagle (1974, p. 279), "na passagem do regime monárquico para o republicano foram mantidas as normas gerais de atuação do Estado em matéria de educação", o federalismo inaugurado pelo novo regime deu azo aos Estados para organizarem a instrução pública segundo os interesses locais. Nesse processo, as Escolas Normais constituíram o palco privilegiado do debate educacional e acabaram por impor normas não só ao ensino elementar, mas também ao ensino secundário e mesmo superior. À medida que o regime se estabilizava no plano federal em direção à chamada "política dos governadores", cujo ingrediente básico consistia em assegurar o domínio das oligarquias nos Estados, as Escolas Normais orientavam-se, de forma crescente a partir da virada do século, pela estruturação adotada em São Paulo. Nesse Estado, o modelo adotado estava baseado em escolas anexas, que serviram de embrião aos futuros grupos escolares e que constituíram uma fonte importante da própria clientela da Escola Normal. A valorização crescente da prática profissional e a adaptação da formação geral ao contexto local, ensaiadas em São Paulo, são características comuns encontradas nas Escolas Normais de todo o País por volta de 1910. Porém, ao contrário de São Paulo, onde ainda se formava cerca de um terço de professores homens no início do século, na maioria dos Estados, a feminização do 
magistério foi muito mais acentuada em detrimento, é claro, da sua profissionalização. ${ }^{2}$ As razões podem ser vistas de forma eloqüente no discurso do governador do Piauí, ao reabrir, em 1910, a Escola Normal no Estado, desta feita só para o sexo feminino:

Duas razões principais atuaram no meu espírito para semelhante preferência. A primeira e a mais poderosa foi a natural aptidão para desempenhar melhor esta função que a mulher possui; mais afetiva que o homem, ela está, por isso, muito mais apta a ensinar crianças e acompanhar-lhes os primeiros albores da inteligência. A segunda razão foi a exigüidade dos vencimentos que o Estado oferece aos professores. Com a carestia atual de vida, é absurdo pensar em obter preceptores dedicados ao magistério, pagando os minguados ordenados do orçamento. A mulher, porém, mais fácil de contentar e mais resignada, e quase sempre assistida pelo marido, pelo pai ou irmão, poderá aceitar o professorado e desempenhálo com assiduidade e dedicação, não obstante a parcimônia da retribuição dos serviços (Castelo Branco, 1995, p. 67).

\section{Referências bibliográficas}

ALMEIDA, Jane Soares de. Mulher e educação : a paixão pelo possível. São Paulo : Unesp, 1998.

ALMEIDA, José Ricardo Pires de. História da instrução pública no Brasil (1500-1889). São Paulo : Educ; Brasília : Inep/MEC, 1989.

ARAÚJO, Maria Marta. Origens e tentativas de organização da rede escolar do Rio Grande do Norte : da Colônia à Primeira República. Campinas, 1979. Dissertação (Mestrado) - Universidade Estadual de Campinas.

BELLO, Ruy. Subsídios para a história da educação em Pernambuco. Recife : Secretaria da Educação e Cultura de Pernambuco, 1978.

BITTENCOURT, Agnello. Pródromos educacionais do Amazonas. Manaus : Instituto Histórico e Geográfico do Amazonas, 1981.

BRZEZINSKI, Iria. A formação do professor para o início da escolarização. Goiânia : Editora da Universidade Católica de Goiás, 1987.

CANEZIN, Maria Teresa, LOUREIRO, Walderês Nunes. A Escola Normal em Goiás. Goiânia : Editora da Universidade Federal de Goiás, 1994.

CASTELO BRANCO, Pedro Vilarinho Castelo. Mulheres plurais : a condição feminina em Teresina na Primeira República. Recife, 1995. Dissertação (Mestrado) - Universidade Federal de Pernambuco.

COUTINHO, José Maria. História da Educação no Espírito Santo. Vitória : Departamento de Educação e Cultura, 1993.

DESAULNIERS, Julieta Beatriz Ramos. O campo religioso e a formação de trabalhadores. História da Educação, Pelotas, v. 1, n. 1, p. 104-121, abr. 1997.

FIORI, Neide Almeida. Aspectos da evolução do ensino público. 2. ed. Florianópolis : Editora da Universidade Federal de Santa Catarina, 1991.

HAIDAR, Maria de Lourdes Mariotto. O ensino secundário no Império brasileiro. São Paulo : Grijalbo, Edusp, 1972.

MARCÍLIO, Humberto. História do ensino em Mato Grosso. Cuiabá : Secretaria de Educação e Cultura, 1963.

MELLO, José Baptista de. Evolução do ensino na Paraíba. 3. ed. João Pessoa : Secretaria da Educação e Cultura, 1996.

\footnotetext{
2 As teses recentes de Jane Soares de Almeida (1998) sobre a feminizacão do magistério, centradas no caso do Estado de São Paulo, a nosso ver, ficariam bastante reforcadas se estendermos sua análise a Estados não marcados tão profundamente pela imigração e industrialização, no período aqui considerado.
} 
MENDONÇA, José Antonio Nunes. A educação em Sergipe. Aracaju : Livraria Regina, 1958.

MOACYR, Primitivo. A instrução e as províncias. São Paulo : Ed. Nacional, 1939-1940. 3 v.

NAGLE, Jorge. Educação e sociedade na Primeira República. São Paulo : EPU, Edusp, 1974.

NUNES, Maria Thetis. História da educação em Sergipe. Rio de Janeiro : Paz e Terra; Aracaju : SEC/SE, UFSE, 1984.

OLYMPIO, Mathias (Org.). A instrução pública no Piauí. Teresina : Sociedade Auxiliadora de Instrução, 1922.

PARAÍBA. Coleção dos Atos dos Poderes Legislativo e Executivo do Estado da Paraíba em 1892. Paraíba : Imprensa Oficial, 1913.

SAFFIOTI, Heleieth. A mulher na sociedade de classes : mito e realidade. Petrópolis : Vozes, 1976.

SALDANHA, Lilian Maria Leda, MELO, Maria Alice. Reconstrução histórica do processo de formação primária no Maranhão (1889-1930). São Luís, 1996. mimeo.

SOUZA, Joaquim Moreira de. Estudo sobre o Ceará. Rio de Janeiro : Instituto Nacional de Estudos Pedagógicos, 1955.

TANURI, Leonor Maria. O ensino normal no Estado de São Paulo (1890-1930). São Paulo : Faculdade de Educação, USP, 1979.

VILELA, Humberto. A Escola Normal de Maceió (1869-1937). Maceió : Secretaria de Educação e Cultura, 1982.

VILLELA, Heloisa. A primeira Escola Normal do Brasil. In: NUNES, Clarice (Org.). O passado sempre presente. São Paulo : Cortez, 1992.

Recebido em 14 de outubro de 1998.

Wojciech Andrzej Kulesza, doutor em Filosofia e História da Educação pela Universidade Estadual de Campinas (Unicamp), é professor adjunto do Departamento de Metodologia da Educação da Universidade Federal da Paraíba (UFPB).

\section{Abstract}

The creation of public Normal Schools in the provinces had to be adapted to the secondary education, essentially masculine and dedicated to the preparation for the entrance in the higher education, and that always had as model the Colégio Pedro II in Rio de Janeiro. Several provincial Liceus constituted fundamental reference for the development of the normal teaching, lending its teachers, its facilities and its regulations for the new schools. In this confrontation between the emanated norms of the central power and the local rules, several institutional forms were tried in which the two schools finish influencing mutually, at the same time that were going being configured as different schools. As result of that process, without continuity solution in the transition of the Empire for the Republic, emerges during the first decade of our century in whole national territory, a Normal School essentially feminine, endowed with enclosed model primary schools destined to the pedagogic practice, and that launched the process of professionalization of our teachers.

Key-Words: primary teaching; school institutions; history of education. 